\title{
A Mesoporous Metal-Organic Framework with Permanent Porosity
}

\author{
Xi-Sen Wang, ${ }^{\dagger}$ Shengqian $\mathrm{Ma},{ }^{\dagger}$ Daofeng Sun, ${ }^{\dagger}$ Sean Parkin, ${ }^{\ddagger}$ and \\ Hong-Cai Zhou*† \\ Department of Chemistry \& Biochemistry, Miami University, Oxford, Ohio, \\ USA, 45056 \\ and Department of Chemistry, University of Kentucky, Lexington, KY, USA, 40506
}

General Consideration. Commercially available reagents were used as received without further purification. Infrared spectra were obtained on a PerkinElmer Spectrum One FT-IR with universal diamond ATR sampling accessory in the $650-4000 \mathrm{~cm}^{-1}$ region. Elemental analyses $(\mathrm{C}, \mathrm{H}, \mathrm{N})$ were performed by Canadian Microanalytical Service Ltd. with a PerkinElmer 240 elemental analyzer. Thermal gravimetric analysis (TGA) was performed under $\mathrm{N}_{2}$ on a PerkinElmer TGA 7 instrument. A Beckman Coulter SA3100 surface area analyzer was used to measure gas adsorption. Solvent-accessible volume was calculated using PLATON.

Synthesis of mesoMOF-1. A mixture of $\mathrm{H}_{3}$ TATAB $\left(0.01 \mathrm{~g}, 2.06 \times 10^{-5} \mathrm{~mol}\right)$ and $\mathrm{Cu}\left(\mathrm{NO}_{3}\right)_{2} \cdot 2.5 \mathrm{H}_{2} \mathrm{O}\left(0.025 \mathrm{~g}, 1.07 \times 10^{-4} \mathrm{~mol}\right)$ in $1.5 \mathrm{~mL}$ DMF were sealed in a Pyrex tube under vacuum and heated at a constant rate of $1{ }^{\circ} \mathrm{C} / \mathrm{min}$ to $95^{\circ} \mathrm{C}$, kept at that temperature for 1 day, and cooled to room temperature at a constant rate of $0.1^{\circ} \mathrm{C} / \mathrm{min}$. The resulting blue block crystals were washed with DMF several times to give pure mesoMOF-1 with formula 
$\mathrm{Cu}_{3}\left(\mathrm{C}_{24} \mathrm{H}_{15} \mathrm{~N}_{6} \mathrm{O}_{6}\right)_{2}\left(\mathrm{H}_{2} \mathrm{O}\right)_{3} \cdot 8 \mathrm{C}_{3} \mathrm{H}_{7} \mathrm{NO} \cdot 9 \mathrm{H}_{2} \mathrm{O}\left(0.012\right.$ g, yield: 68\%). IR (cm $\left.{ }^{-1}\right): 2922(\mathrm{~s}), 2853(\mathrm{~m})$, 1666(m), 1617(m), 1594(m), $1515(\mathrm{w}), 1487(\mathrm{~s}), 1386(\mathrm{~s}), 1345(\mathrm{~s}), 1239(\mathrm{~m}), 1178(\mathrm{~s}), 1094(\mathrm{~m})$, 1015 (w), 859(m), 806(m), 780(s), 700(m). Elemental analysis (\%) calcd for 1: C 44.16, H 5.66, N 14.30; found: C 42.32, H 5.71, N 14.48.

Synthesis of mesoMOF-1·HX. The compound mesoMOF-1 was soaked in methanol for one day to remove DMF solvates, and the methanol extract was decanted. The material was then soaked in a $\mathrm{HX}$ solution $(\mathrm{X}=\mathrm{F}, \mathrm{Cl}$, or $\mathrm{Br}$; $p H$ value around 3 monitored by using a $p H$ meter) overnight to prepare the mesoporous material leading to a color change from blue to green, presumably because of the formation of $\mathrm{Cu}-\mathrm{X}$ bonds at axial positions of the paddlewheel units. ${ }^{1}$

Measurement of voids and channels. Measurements of void and channel sizes were based on distances from atom to atom centers.

$\mathbf{N}_{2}$ Adsorption Measurements. The sample was soaked in anhydrous $\mathrm{CH}_{3} \mathrm{OH}$ for 24 hours, and the extract was discarded to remove $\mathrm{H}_{2} \mathrm{O}$ solvates. The samples were then soaked in $\mathrm{CHCl}_{3}$ for four days and fresh $\mathrm{CHCl}_{3}$ was exchanged everyday to completely remove $\mathrm{CH}_{3} \mathrm{OH}$ solvates. After the removal of $\mathrm{CHCl}_{3}$ by decanting, the sample was dried under vacuum $(<$ $10^{-3}$ torr $)$ at room temperature $\left(25^{\circ} \mathrm{C}\right)$ for one hour, leading to a color change from green to turquoise. Before the measurement, the sample was dried again by using the "outgas" function of the surface area analyzer for $15 \mathrm{~min}$ at $80^{\circ} \mathrm{C}$ to remove all residue solvents in the channels. A sample of $43.0 \mathrm{mg}$ was used for $\mathrm{N}_{2}$ adsorption measurement, and was maintained at $77 \mathrm{~K}$ with liquid nitrogen. 


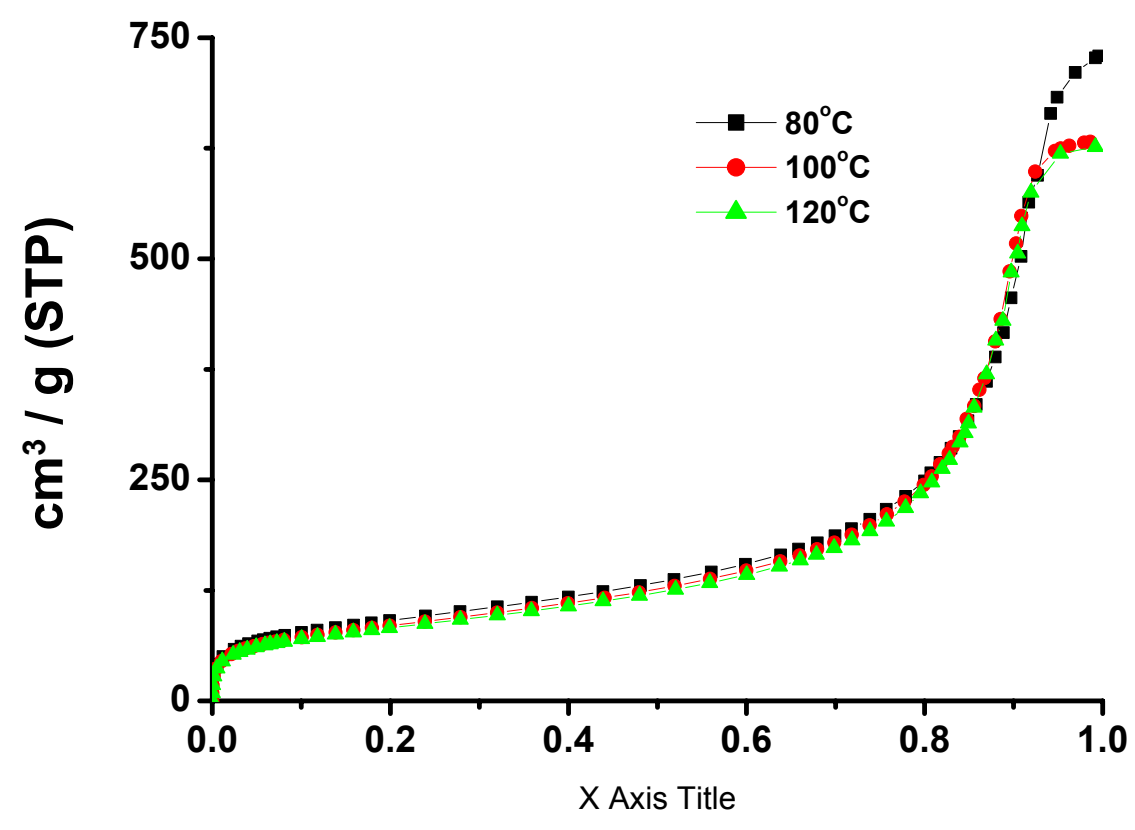

Figure S1 Gas adsorption isotherms (77 K) of mesoMOF-1-HX activated at 80, 100, and $120^{\circ} \mathrm{C}$.

\section{Reference}

1. Jezierska, J.; Glowiak, T.; Ozarowski, A., Yablokov, Y. V.; Rzaczynska, Z. Inorg. Chim. Acta, 1998, $275,28$. 